\title{
Effects of Chronic Antidepressant Treatments on Serotonin Transporter Function, Density, and mRNA Level
}

\author{
Saloua Benmansour, ${ }^{1}$ Marco Cecchi, ${ }^{1}$ David A. Morilak, ${ }^{1}$ Greg A. Gerhardt,, ${ }^{4}$ Martin A. Javors, ${ }^{1,2}$ \\ Georgianna G. Gould, ${ }^{1}$ and Alan Frazer ${ }^{1,3}$
}

Departments of ${ }^{1}$ Pharmacology and ${ }^{2}$ Psychiatry, University of Texas Health Science Center, San Antonio, Texas 78284, ${ }^{3}$ South Texas Veterans Health Care System, San Antonio, Texas 78284, and ${ }^{4}$ Departments of Anatomy and Neurobiology, University of Kentucky, Lexington, Kentucky 40536

To investigate functional changes in the brain serotonin transporter (SERT) after chronic antidepressant treatment, several techniques were used to assess SERT activity, density, or its mRNA content. Rats were treated by osmotic minipump for $21 \mathrm{~d}$ with the selective serotonin reuptake inhibitors (SSRIs) paroxetine or sertraline, the selective norepinephrine reuptake inhibitor desipramine (DMI), or the monoamine oxidase inhibitor phenelzine. High-speed in vivo electrochemical recordings were used to assess the ability of the SSRI fluvoxamine to modulate the clearance of locally applied serotonin in the CA3 region of hippocampus in drug- or vehicle-treated rats. Fluvoxamine decreased the clearance of serotonin in rats treated with vehicle, DMI, or phenelzine but had no effect on the clearance of serotonin in SSRI-treated rats. SERT density in the CA3 region of the hippocampus of the same rats, assessed by quantitative autoradiography with tritiated cyanoimipramine $\left(\left[{ }^{3} \mathrm{H}\right] \mathrm{CN}-\mathrm{IMI}\right)$, was decreased by $80-90 \%$ in SSRI-treated rats but not in those treated with phenelzine or DMI. The serotonin content of the hippocampus was unaffected by paroxetine or sertraline treatment, ruling out neurotoxicity as a possible explanation for the SSRI-induced decrease in SERT binding and alteration in 5-HT clearance. Levels of mRNA for the SERT in the raphe nucleus were also unaltered by chronic paroxetine treatment. Based on these results, it appears that the SERT is downregulated by chronic administration of SSRIs but not other types of antidepressants; furthermore, the downregulation is not caused by decreases in SERT gene expression.

Key words: serotonin transporter; antidepressants; in vivo electrochemistry; $\left[{ }^{3} \mathrm{H}\right] \mathrm{CN}-I M I$ binding; mRNA for the SERT; dorsal hippocampus
The serotonin transporter (SERT) is the primary initial target for many classes of antidepressants, including selective serotonin reuptake inhibitors (SSRIs) (Frazer, 1997). SSRIs rapidly inhibit the uptake of serotonin (5-HT). However, maximal antidepressant effects are obtained only after weeks or even months of repeated treatment, suggesting that in addition to the inhibition of serotonin reuptake, other longer-term, adaptive changes occur that contribute to therapeutic efficacy. Most long-term studies of antidepressants have focused on their effects on autoreceptors or postsynaptic receptors and the responses they elicit (Blier and Bouchard, 1994; Auerbach and Hjorth, 1995). Less well studied is the effect of long-term SSRI treatment on SERT function or 5-HT uptake (Piñeyro et al., 1994), even though it is becoming apparent, based primarily on studies performed using cells in culture, that the SERT is subject to various type of regulatory influences (Qian et al., 1997; Ramamoorthy et al., 1998; Ramamoorthy and Blakely, 1999).

Although there is little research on antidepressant-induced regulation of SERT function in vivo, there have been numerous studies of the effects of such treatment on the binding of ligands to the SERT or its mRNA content. Such studies have yielded conflicting results, with some studies reporting increases (Hrdina

Received June 24, 1999; revised Sept, 13, 1999; accepted Sept. 16, 1999.

This work was supported by United States Public Health Service Grants, MH57001 (A.F.), MH53851 (D.A.M.), and MH01245 (G.A.G.). We thank Dr. Aurelio Galli for critical reading of this manuscript and helpful discussions.

Correspondence should be addressed to Dr. Saloua Benmansour, Department of Pharmacology, University of Texas Health Science Center at San Antonio, 7703 Floyd Curl Drive, San Antonio, TX 78284-7764. E-mail: benmansour@uthscsa.edu. Copyright (C) 1999 Society for Neuroscience 0270-6474/99/1910494-08\$05.00/0 and Vu, 1993; Lopez et al., 1994), decreases (Brunello et al., 1987; Kovachich et al., 1992; Lesch et al., 1993; Watanabe et al., 1993; Kuroda et al., 1994; Piñeyro et al., 1994; Neumaier et al., 1996), or no change (Cheetham et al., 1993; Burnet et al., 1994; Spurlock et al., 1994; Linnet et al., 1995; Gobbi et al., 1997) in these parameters. The variability in results may be attributable in part to differences in the type of antidepressant used or dose used as well as the route and frequency of drug administration. Often rats were treated once a day intraperitoneally or, for short-acting drugs, twice daily. Given the half-lives of most antidepressants in rats, this produced a spiked or transient drug exposure compared to the steadier exposure to drug achieved in patients, because the half-lives of these drugs in humans are, in general, considerably longer than in rats.

To control variability in drug exposure of the SERT to drug, we administered antidepressants in this study from osmotic minipumps and measured steady-state serum concentrations to select doses that produced drug concentrations either within or close to the "therapeutic range." Antidepressants were selected that block the uptake of 5-HT selectively (paroxetine and sertraline), the uptake of norepinephrine (NE) selectively (desipramine; DMI), or inhibit monoamine oxidase (MAO; phenelzine). In addition, in vivo chronoamperometry was used to measure serotonin clearance and its modulation by local application of the SSRI fluvoxamine in the CA3 region of rat hippocampus, because it had been established that active clearance of 5-HT in this region is attributable primarily to activity of the SERT (Daws et al., 1998). Finally, the density of SERT-binding sites in the same rats was assessed by quantitative autoradiography, and levels of 
expression of mRNA for the SERT in raphe nuclei were determined by in situ hybridization.

\section{MATERIALS AND METHODS}

Animals. Male Sprague Dawley rats (Harlan Sprague Dawley, Indianapolis, IN) weighing 175-200 gm at the time of initiation of drug treatment were housed individually on a $12 \mathrm{hr}$ light/dark cycle with lights on at 7:00 A.M. and with food and water provided ad libitum. All animal procedures were in strict accordance with the National Institutes of Health Guide for the Care and Use of Laboratory Animals. All efforts were made to minimize both the number of animals used and stress or discomfort to the animal during the experimental procedure.

Chronic drug treatments. Groups of 6-15 rats were treated for $21 \mathrm{~d}$ with various antidepressants. Paroxetine $\left(5 \mathrm{or} 10 \mathrm{mg} \cdot \mathrm{kg}^{-1} \cdot \mathrm{d}^{-1}\right.$; SmithKline Beecham, Harlow, England), sertraline $\left(7.5 \mathrm{mg} \cdot \mathrm{kg}^{-1} \cdot \mathrm{d}^{-1}\right.$; Pfizer, Groton, CT), and desipramine $\left(15 \mathrm{mg} \cdot \mathrm{kg}^{-1} \cdot \mathrm{d}^{-1}\right.$; Sigma, St. Louis, MO), were administered subcutaneously by means of osmotic minipumps (Alza, Palo Alto, CA); phenelzine $\left(5 \mathrm{mg} \cdot \mathrm{kg}^{-1} \cdot \mathrm{d}^{-1}\right.$; Sigma) was given once daily, intraperitoneally, because it is essentially an irreversible inhibitor of MAO. Control groups received vehicle (saline or 50\% ethanol:water, the solvent for paroxetine and sertraline) by osmotic minipumps or daily intraperitoneal injection. Selection of the drug doses was based on an initial set of experiments in which serum drug levels at steady state (after 7-10 d of administration by osmotic minipump) were measured (Table 1). Also, for each drug treatment, the time necessary after removal of the minipumps to reach serum levels of drug $<5 \mathrm{ng} / \mathrm{ml}$ was determined. This occurred $96 \mathrm{hr}$ after stopping paroxetine treatment, $72 \mathrm{hr}$ after desipramine treatment, and $48 \mathrm{hr}$ after sertraline treatment. Blood levels of phenelzine were not measured; these rats were studied $48 \mathrm{hr}$ after the final injection of the drug.

In vivo chronoamperometry. This was performed as described previously (Daws et al., 1998). Carbon fiber electrodes (30 $\mu \mathrm{m}$ tip diameter, 95-175 $\mu \mathrm{m}$ in length) were coated with Nafion to improve the selectivity of the electrode, (Gerhardt et al., 1984), then tested for sensitivity to 5-HIAA (250 $\mu \mathrm{M}$; Sigma) and calibrated in vitro with 5-HT. Only electrodes displaying a selectivity ratio for 5 -HT over 5-HIAA $\geq 1000: 1$ and a linear response $\left(r^{2} \geq 0.997\right)$ to 5 -HT $(0.5-3.0 \mu \mathrm{M})$ were used.

Rats were anesthetized with chloralose $(70 \mathrm{mg} / \mathrm{kg})$-urethane $(700$ $\mathrm{mg} / \mathrm{kg}$ ), and the electrode, attached to a multibarrel micropipette, was positioned in the $\mathrm{CA}_{3}$ region of the dorsal hippocampus. The distance between electrode and pipette tips was 275-325 $\mu \mathrm{m}$. Multibarrel micropipettes were filled with either 5-HT (200 $\mu \mathrm{M}$; Sigma), fluvoxamine (400 $\mu \mathrm{M}$; Pharmacia and Upjohn, Kalamazoo, MI), or desipramine $(400 \mu \mathrm{M})$. The $\mathrm{pH}$ of all solutions was 7.4. All drugs were delivered by pressure ejection in a volume of $20-100 \mathrm{nl}$. Twenty to thirty minutes after lowering of electrode, chronoamperometric recordings were started. Once reproducible electrochemical signals from 5-HT were obtained, drug was applied 60-90 sec before the next application of 5-HT.

High-speed chronoamperometric recordings were made using the Fast-12 system (Quanteon, Denver, CO). Oxidation potentials consisted of $100 \mathrm{msec}$ pulses of $+0.55 \mathrm{~V}$ versus $\mathrm{Ag} / \mathrm{AgCl}$ that were delivered one per second; the electrode was held at a resting potential of $0.0 \mathrm{~V}$ between measurements. The reference electrode was positioned in the superficial cortex. Oxidation and reduction currents were digitally integrated during the last $80 \mathrm{msec}$ of each $100 \mathrm{msec}$ voltage pulse.

Several parameters are obtained from the electrochemical signal produced by exogenous applications of 5-HT. Signal amplitude was maintained between 0.6 and $0.8 \mu \mathrm{M}$ by applying various amount of 5 -HT (4-21 pmol) to facilitate comparison between different treatment groups. Other parameters analyzed were T80, the time it takes for the peak amplitude to be reduced by $80 \%$; T40-80, the time for the signal to decrease from $80 \%$ of its peak value to $40 \%$; and the total time course $(t$ course), the total time for the signal to return to baseline from the time of application of 5-HT.

Autoradiographic procedures. After completing the in vivo chronoamperometry recordings, rats were decapitated, and their brains were frozen quickly on dry ice and stored at $-80^{\circ} \mathrm{C}$ until sectioning. Brain sections $(20 \mu \mathrm{m})$ were cut in a cryostat at $-15^{\circ} \mathrm{C}$, thaw-mounted onto gelatin-coated frozen microscope slides, and dehydrated overnight at $0-4^{\circ} \mathrm{C}$. Slide-mounted sections were incubated with radioligand and were then washed, dried, and placed into spring-loaded cassettes and apposed to tritium-sensitive film $\left(\left[{ }^{3} \mathrm{H}\right]\right.$ Ultrofilm; Amersham, Uppsala, Sweden) at room temperature. Films were developed using Kodak (Eastman Kodak, Rochester, NY) GBX developer and fixed in Kodak GBX fixer. Autoradiograms were analyzed using NIH Image and the Scion software package. Quantitation was achieved using plastic-embedded tritium standards (American Radiolabeled Chemicals) calibrated using brain mash sections. Brain structures were visualized by staining sections with thionin and were identified using the atlas of Paxinos and Watson (1986).

Serotonin uptake sites were measured using $\left[{ }^{3} \mathrm{H}\right]$ cyanoimipramine as previously described (Kovachich et al., 1988). Different treatments groups were run through washes with buffer solutions to avoid interassay variability in SERT autoradiography. Brain sections were incubated with 1nm [ $\left.{ }^{3} \mathrm{H}\right] \mathrm{CN}-\mathrm{IMI}$ ( $80-85 \mathrm{Ci} / \mathrm{mmol}$; American Radiolabeled Chemicals) in a buffer consisting of $50 \mathrm{~mm}$ Tris, $\mathrm{pH} 7.4$, and $120 \mathrm{~mm} \mathrm{NaCl}$ at $4^{\circ} \mathrm{C}$ for $24 \mathrm{hr}$. Nonspecific binding was defined using $5 \mu \mathrm{M}$ sertraline and was $\sim 5 \%$ of total binding. After incubation, sections were washed in cold buffer for $60 \mathrm{~min}$ at $4^{\circ} \mathrm{C}$, dipped in cold distilled water, and then dried on a slide warmer at $60^{\circ} \mathrm{C}$. Dried slide-mounted sections were apposed to tritium-sensitive film for 12-14 d. Measurements were taken at the level of plate 33 of the atlas of Paxinos and Watson (1986). The concentration of [ $\left.{ }^{3} \mathrm{H}\right] \mathrm{CN}$-IM I used is $\sim 8 \times$ its $K_{\mathrm{D}}$ value (Kovachich et al., 1988), so the values obtained approximate $\mathrm{B}_{\max }$ values.

HPLC analysis of 5-HT content. Hippocampi from the contralateral hemispheres were used to determine levels of 5-HT by HPLC coupled with electrochemical detection as described by Hall et al. (1989). The levels of monoamines are expressed as nanograms per gram wet weight of tissue.

HPLC analysis of serum drug levels. Serum was collected after 7-10 d of treatment (to measure steady-state drug levels) or at the end of the electrochemical recording session. Serum concentrations of sertraline, paroxetine, and desipramine were determined by HPLC with a Waters spherisorb S5 CN column and UV detection at $214 \mathrm{~nm}$. Samples were spiked with doxepin as an internal standard. Drugs were extracted from plasma with a hexane-isopropanol mixture $(19: 1, \mathrm{v} / \mathrm{v})$, then backextracted into a phosphate buffer, $\mathrm{pH}$ 2.5. Aliquots of the backextractions were injected into the HPLC. Plasma drug concentrations are expressed in nanograms per milliliter.

In situ hybridization. Animals treated chronically with paroxetine (10 $\mathrm{mg} \cdot \mathrm{kg}^{-1} \cdot \mathrm{d}^{-1}$ ) or vehicle were killed by rapid decapitation. Brains were removed, frozen by immersion in isopentane on dry ice, and stored at $-70^{\circ} \mathrm{C}$ until cut. Alternate series of $20 \mu \mathrm{m}$ sections were cut through the dorsal and median raphe on a cryostat, thaw-mounted onto silane-coated glass microscope slides, fixed for $15 \mathrm{~min}$ in $4 \%$ paraformaldehyde, dehydrated, and stored at $-70^{\circ} \mathrm{C}$. One series was used for in situ hybridization, and the adjacent series was used for staining with cresyl violet. Sections from all brains were processed together in one hybridization.

Methods for in situ hybridization were essentially as previously described (Domyancic and Morilak, 1997), with minor modification. After linearizing the cDNA template of the SERT (obtained from Dr. Stanley Watson, University of Michigan), the 660 nucleotide riboprobe was transcribed with the addition of $\alpha-{ }^{35} \mathrm{~S}$-UTP (New England Nuclear), to a specific activity of $2 \times 10^{9} \mathrm{cpm} / \mu \mathrm{g}$. All prehybridization solutions were treated with diethylpyrocarbonate and sterilized. Brain sections were thawed, hydrated, acetylated, and rinsed in $2 \times$ SSC $(1 \times$ SSC is $150 \mathrm{~mm}$ sodium chloride, $15 \mathrm{~mm}$ sodium citrate, $\mathrm{pH}$ 7.2). Sections were then dehydrated, delipidated, and air-dried. Hybridization buffer consisted of $50 \mathrm{~mm}$ sodium phosphate, $3 \times \mathrm{SSC}, 5 \times$ Denhardt's solution, $0.1 \mathrm{mg} / \mathrm{ml}$ salmon sperm DNA, $0.1 \mathrm{mg} / \mathrm{ml}$ yeast tRNA, $10 \mathrm{~mm}$ dithiothreitol, $10 \%$ dextran sulfate, and $50 \%$ deionized formamide, to which radiolabeled riboprobe was added to a final concentration of $4 \times 10^{7} \mathrm{cpm} / \mathrm{ml}(\sim 20$ $\mathrm{ng} / \mathrm{ml}$ ). Sections were incubated overnight in a sealed humidified cham-

Table 1. Serum concentrations of the antidepressants

\begin{tabular}{|c|c|c|c|}
\hline \multirow[b]{2}{*}{ Drug } & \multirow[b]{2}{*}{$\begin{array}{l}\text { Dose } \\
\mathrm{mg} \cdot \mathrm{kg}^{-1} \cdot \mathrm{d}^{-1}\end{array}$} & \multicolumn{2}{|l|}{ Serum level } \\
\hline & & $\begin{array}{l}\text { Steady-state } \\
(\mathrm{ng} / \mathrm{ml})\end{array}$ & $\begin{array}{l}\text { Therapeutic } \\
(\mathrm{ng} / \mathrm{ml})\end{array}$ \\
\hline Paroxetine $(n=7)$ & 10 & $411 \pm 78^{a}$ & $5-100$ \\
\hline Paroxetine $(n=9)$ & 5 & $80 \pm 22$ & \\
\hline Sertraline $(n=9)$ & 7.5 & $284 \pm 96$ & $30-150$ \\
\hline Desipramine $(n=5)$ & 15 & $348 \pm 80$ & $125-600$ \\
\hline
\end{tabular}

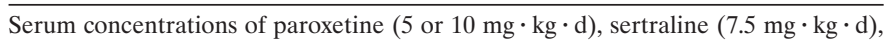
or desipramine $(15 \mathrm{mg} \cdot \mathrm{kg} \cdot \mathrm{d})$ were determined after $7-10 \mathrm{~d}$ of treatments by osmotic minipump, time at which steady-state should be achieved given the half-lives of these drugs in rats. The values obtained were compared to therapeutic drug level guidelines (Kaye et al., 1989).

${ }^{a}$ Mean \pm SEM. 
ber at $60^{\circ} \mathrm{C}$. Control sense-strand probe was applied to a small number of sections to verify specificity of the label.

All post-hybridization solutions contained $1 \mathrm{~mm}$ dithiothreitol. After hybridization, excess probe was removed by rinsing in four washes of $2 \times$ SSC and digesting with RNase A $\left(20 \mu \mathrm{g} / \mathrm{ml}, 30 \mathrm{~min}\right.$ at $\left.37^{\circ} \mathrm{C}\right)$. Sections were then taken through a series of increasingly stringent washes: $10 \mathrm{~min}$ each in $1 \times, 0.5 \times$, and $0.2 \times \mathrm{SSC}$ at $24^{\circ} \mathrm{C}$, followed by $3 \times 1 \mathrm{hr}$ in $0.1 \times$ $\mathrm{SSC}$ at $60^{\circ} \mathrm{C}$. They were then rinsed in $1 \times \mathrm{SSC}$, dehydrated, and apposed, along with ${ }^{14} \mathrm{C}$-radioactive standards, to Kodak Biomax MR x-ray film for $24 \mathrm{hr}$ before developing.

Digitized autoradiographic film images were captured with a Sony XC-77 CCD camera coupled to a Scion LG-3 capture board in a PowerMac 7100 computer. Integrated signal density overlying the dorsal and median raphe, calibrated from the standards on each film and expressed in standard units of nanocuries per milligram, was measured in three to six sections per brain, corresponding approximately to plate 49 in the atlas of Paxinos and Watson (1986), using the NIH Image software package (version 1.55; Wayne Rasband, National Institutes of Health, Bethesda, MD).

Statistical analysis. Data were analyzed by $t$ test or by one-way ANOVA followed by Newman-Keuls post hoc multiple comparisons, with significance determined at $p<0.05$.

\section{RESULTS}

\section{Drug levels in serum}

Steady-state levels of antidepressants were measured after 7-10 d of continuous infusion by osmotic minipump. The mean steadystate serum concentration obtained after administration of 10 $\mathrm{mg} / \mathrm{kg}$ of paroxetine, $411 \pm 78 \mathrm{ng} / \mathrm{ml}$ (Table 1) was much higher than that measured $(80 \pm 20 \mathrm{ng})$ after giving half the dose. Doses used for paroxetine $(5 \mathrm{mg} / \mathrm{kg})$ and desipramine $(15 \mathrm{mg} / \mathrm{kg})$ produced serum concentrations found within the therapeutic range (Table 1). The higher dose of paroxetine $(10 \mathrm{mg} / \mathrm{kg})$ produced serum concentrations larger than those recommended therapeutically (Table 1); however, because this dose was used by others examining the effect of paroxetine on SERT function (Piñeyro et al., 1994), we used it also. The dose of sertraline used caused somewhat higher mean serum concentrations than those recommended therapeutically (Table 1). However, when the dose was lowered to $5 \mathrm{mg} / \mathrm{kg}$, the mean steady-state levels produced were considerably below those recommended therapeutically.

Serum levels of the drugs at the end of each experiment were also measured to rule out effects caused by the presence of residual drug. At $48 \mathrm{hr}$ after cessation of paroxetine $(10 \mathrm{mg} / \mathrm{kg})$ treatment (which is the common washout time used in many

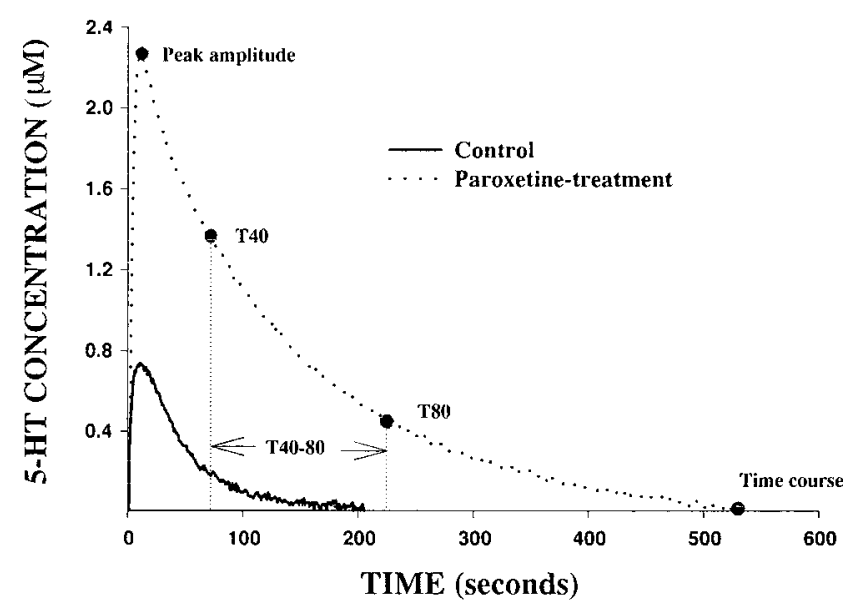

Figure 1. Representative electrochemical signals generated by the local application of the same amount of 5-HT (24 pmol) into the CA3 region of a control (solid line) or a paroxetine-treated rat (dashed line). For clarity, only the oxidation current curves are shown.

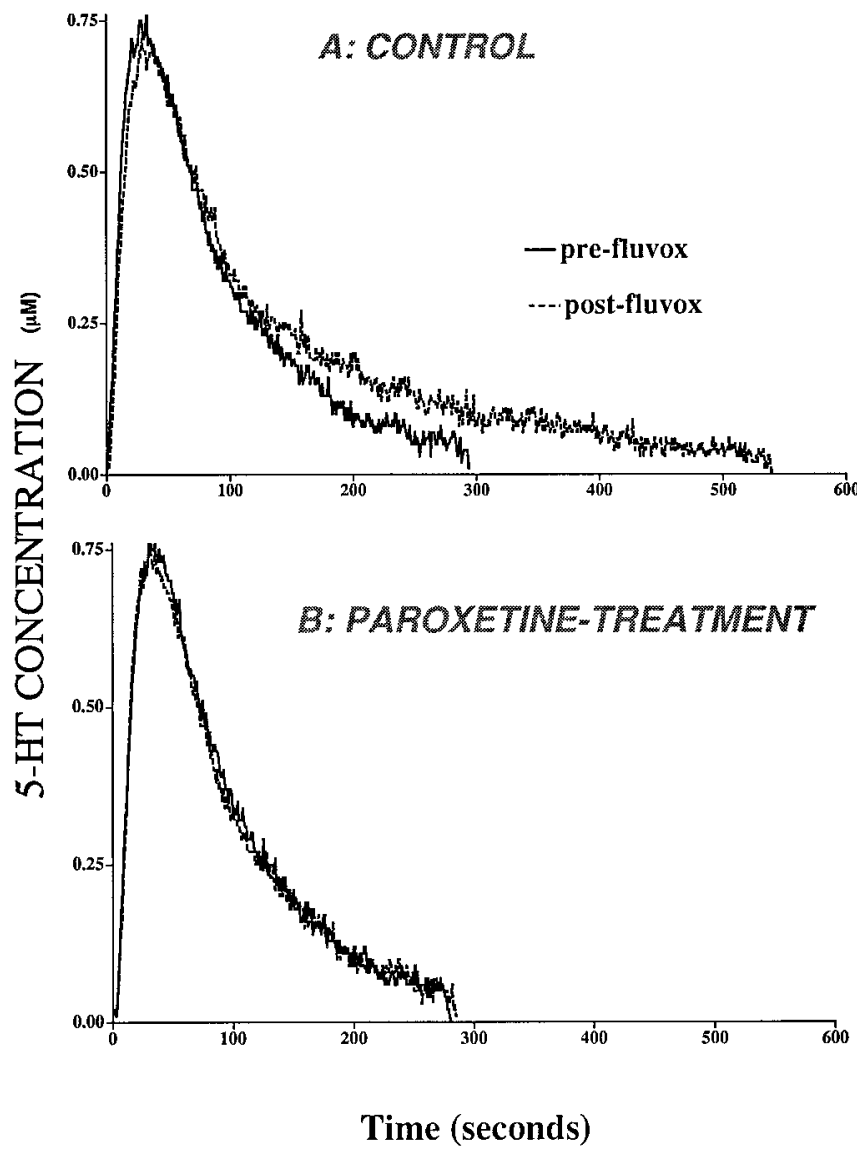

Figure 2. Representative 5-HT electrochemical signals from the CA3 region of dorsal hippocampus in a control $(A)$ and a paroxetine-treated rat $(B)$ before administration of fluvoxamine (solid line). The signal was generated by local application of 5-HT. The amount of 5-HT applied was 26 pmol for the control rat and 8 pmol for the paroxetine rat. The effect of local application of fluvoxamine on 5-HT clearance is illustrated by the dashed line. Fluvoxamine was pressure-ejected 60-90 sec before the next application of 5-HT. For clarity, only the oxidation current curves are shown.

studies, e.g., Piñeyro et al., 1994), the mean serum paroxetine level was still appreciable, $53 \pm 22 \mathrm{ng} / \mathrm{ml}(n=4)$. After $96 \mathrm{hr}$ of washout, the paroxetine concentration fell to below $5 \mathrm{ng} / \mathrm{ml}$. Washout periods for desipramine and sertraline to fall to below $5 \mathrm{ng} / \mathrm{ml}$ were 76 and $48 \mathrm{hr}$, respectively (data not shown). In 12 of 23 rats chronically treated with the SSRIs (paroxetine or sertraline), serum concentration of drugs after washout was zero. The highest serum concentration of SSRIs ( $4 \mathrm{ng} / \mathrm{ml}$ ) was found only in three animals. It is true that such a value translates to a serum concentration of $\sim 12 \mathrm{nM}$, which is $\sim 2$ and 11 times greater than the $k_{\mathrm{i}}$ values of these drugs (sertraline and paroxetine, respectively) for the inhibition of the 5-HT uptake (Tulloch and Johnson, 1992). However, this represents the total plasma concentration, and both paroxetine and sertraline are highly bound to plasma proteins, 95-99\% (Frazer and Morilak, 1998). Thus, the "free" concentration of these drugs, which is the fraction capable of movement into the extracellular fluid of brain, is below the $k_{\mathrm{i}}$ values of these drugs for the SERT. Consistent with this, there was no difference in the parameters measured in the 12 rats that had no SSRI present and those whose values ranged up to 4 $\mathrm{ng} / \mathrm{ml}$. Also, it should be noted that the $\left[{ }^{3} \mathrm{H}\right] \mathrm{CN}-\mathrm{IMI}$-binding 


\begin{tabular}{|c|c|c|c|c|c|}
\hline Treatment & Fluvoxamine & Amplitude $(\mu \mathrm{M})$ & $\mathrm{T} 80(\mathrm{sec})$ & $\mathrm{T} 40-80(\mathrm{sec})$ & Time course $(\mathrm{sec})$ \\
\hline Control $(n=15)^{b}$ & $\begin{array}{l}\text { Pre } \\
\text { Post }\end{array}$ & $\begin{array}{l}0.80 \pm 0.08^{a} \\
0.75 \pm 0.06\end{array}$ & $\begin{array}{l}106 \pm 12 \\
141 \pm 14^{*}\end{array}$ & $\begin{array}{l}68 \pm 9 \\
93 \pm 10^{*}\end{array}$ & $\begin{array}{l}241 \pm 20 \\
376 \pm 30^{*}\end{array}$ \\
\hline Paroxetine $(10 \mathrm{mg})(n=8)$ & $\begin{array}{l}\text { Pre } \\
\text { Post }\end{array}$ & $\begin{array}{l}0.78 \pm 0.13 \\
0.70 \pm 0.12\end{array}$ & $\begin{array}{l}108 \pm 9 \\
114 \pm 10\end{array}$ & $\begin{array}{l}68 \pm 5 \\
73 \pm 7\end{array}$ & $\begin{array}{l}239 \pm 11 \\
250 \pm 15\end{array}$ \\
\hline Paroxetine $(5 \mathrm{mg})(n=7)$ & $\begin{array}{l}\text { Pre } \\
\text { Post }\end{array}$ & $\begin{array}{l}0.68 \pm 0.12 \\
0.62 \pm 0.10\end{array}$ & $\begin{array}{l}103 \pm 6 \\
114 \pm 10\end{array}$ & $\begin{array}{l}56 \pm 4 \\
62 \pm 4\end{array}$ & $\begin{array}{l}184 \pm 18 \\
218 \pm 15\end{array}$ \\
\hline Sertraline $(n=8)$ & $\begin{array}{l}\text { Pre } \\
\text { Post }\end{array}$ & $\begin{array}{l}0.78 \pm 0.10 \\
0.72 \pm 0.09\end{array}$ & $\begin{array}{l}67 \pm 5 \\
72 \pm 7\end{array}$ & $\begin{array}{l}42 \pm 3 \\
46 \pm 4\end{array}$ & $\begin{array}{l}155 \pm 11 \\
165 \pm 12\end{array}$ \\
\hline Desipramine $(n=7)$ & $\begin{array}{l}\text { Pre } \\
\text { Post }\end{array}$ & $\begin{array}{l}0.82 \pm 0.10 \\
0.82 \pm 0.10\end{array}$ & $\begin{array}{l}111 \pm 15 \\
136 \pm 18^{*}\end{array}$ & $\begin{array}{l}67 \pm 8 \\
86 \pm 10^{*}\end{array}$ & $\begin{array}{l}228 \pm 27 \\
316 \pm 29^{*}\end{array}$ \\
\hline Phenelzine $(n=6)$ & $\begin{array}{l}\text { Pre } \\
\text { Post }\end{array}$ & $\begin{array}{l}0.58 \pm 0.11 \\
0.62 \pm 0.12\end{array}$ & $\begin{array}{c}91 \pm 8 \\
127 \pm 10^{*}\end{array}$ & $\begin{array}{l}60 \pm 6 \\
89 \pm 8^{*}\end{array}$ & $\begin{array}{l}196 \pm 11 \\
326 \pm 15^{*}\end{array}$ \\
\hline
\end{tabular}

\footnotetext{
${ }^{a}$ Mean \pm SEM.

${ }^{b}$ Number of rats.

${ }^{*} p<0.001$, paired $t$ test, comparing the effect of fluvoxamine on each parameter in each treatment group.
}

experiments were performed using high concentrations of radioligand $\left(8 \times K_{\mathrm{D}}\right)$, to approximate $\mathrm{B}_{\max }$ values.

\section{Effects on serotonin clearance parameters}

Figure 1 shows the electrochemical signal produced by pressure ejection of the same amount of 5-HT ( $24 \mathrm{pmol})$ into the CA3 region of a control rat and a paroxetine-treated rat. In the paroxetine-treated rat, peak signal amplitude was markedly greater, and the time course of the signal was much longer than that measured in the control rat. To equalize the amplitude of the signal produced by 5 -HT in control and SSRI-treated rats, the amount of 5-HT ejected was reduced so that similar baseline amplitude $(0.6-0.8 \mu \mathrm{M})$ was achieved in all treatment groups. In the SSRI-treated rats, the amount of 5-HT ( $7 \pm 1 \mathrm{pmol})$ required to generate an electrochemical signal of equivalent amplitude to that seen in the control animals was significantly lower $(21 \pm 5$ pmol; $p<0.01)$.

A representative 5-HT signal generated by local application of exogenous serotonin in the CA3 region is shown in Figure 2. Consistent with an earlier report (Daws et al., 1998), local application of desipramine had no effect on the clearance of exogenously applied 5-HT (data not shown), indicating that the norepinephrine transporter does not substantially influence the removal of 5-HT from this region. In control rats, fluvoxamine prolonged the clearance of 5-HT without affecting signal amplitude (Fig. 2). By contrast, in rats treated chronically with paroxetine $(10 \mathrm{mg} / \mathrm{kg})$, local application of fluvoxamine did not prolong the clearance of 5-HT (Fig. 2).

Table 2 summarizes the effects of each antidepressant treatment on various 5-HT signal parameters obtained by in vivo chronoamperometry. In control rats, local application of the SSRI fluvoxamine significantly decreased the clearance of 5-HT from 33 to $56 \%$, depending on the parameter measured. This inhibitory effect of fluvoxamine on 5-HT clearance parameters was also observed to be statistically significant in the groups of rats pretreated with either phenelzine or DMI. By contrast, in rats treated with either dose of paroxetine or with sertraline, the inhibitory effect of local application of fluvoxamine on these signal parameters was essentially abolished. For comparative purposes, the fluvoxamine-induced changes in the T80 value for

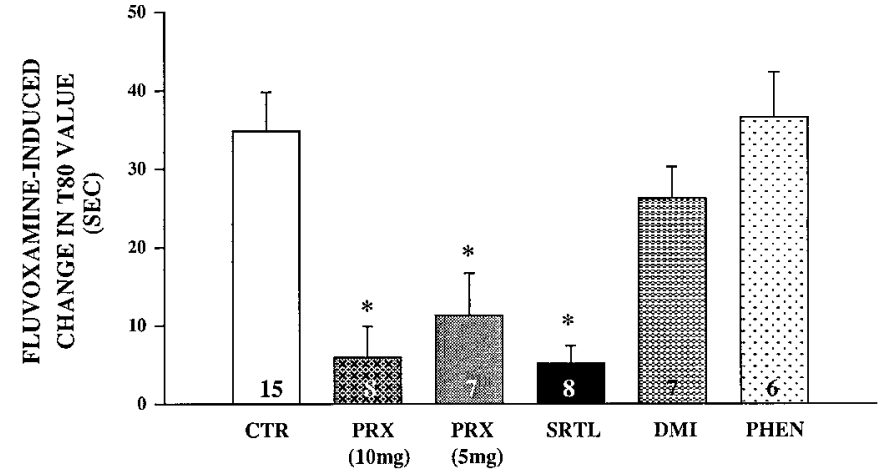

Figure 3. Effects of antidepressants on fluvoxamine-induced changes in the T80 parameter of 5-HT clearance. Electrochemical recordings were performed in the $\mathrm{CA} 3$ region of dorsal hippocampus of rats treated for $21 \mathrm{~d}$ with paroxetine $(P R X ; 5$ or $10 \mathrm{mg})$, sertraline $(S R T L)$, desipramine $(D M I)$, phenelzine $(P H E N)$, or vehicle $(C T R)$. Fluvoxamine was pressure-ejected 60-90 sec before the second application of 5-HT. Bars and brackets represent mean \pm SEM. The number of animals in each group is indicated at the bottom of each bar. ${ }^{*} p<0.01$ comparison of each treatment group with control group, ANOVA, Newman-Keuls post hoc comparison.

each treatment group are shown in Figure 3. Only in rats treated with SSRIs was the fluvoxamine-induced change in the T80 value significantly less from that measured in the control rats. Similar results were obtained with the other clearance parameters (data not shown).

\section{Effects on SERT density}

Autoradiograms showing the effect of each drug treatment on the binding of $\left[{ }^{3} \mathrm{H}\right] \mathrm{CN}-\mathrm{IMI}$ in multiple brain areas are shown in Figure 4. It is apparent that treatment with the SSRIs markedly reduced binding, whereas treatment with either DMI or phenelzine did not. These values were quantified for the CA3 region of the hippocampus, the same area in which the electrochemical experiments were performed. These results are shown in Figure 5. Chronic treatment of rats with either dose of paroxetine or with sertraline resulted in a very marked reduction of $\left[{ }^{3} \mathrm{H}\right] \mathrm{CN}-\mathrm{IMI}$ 


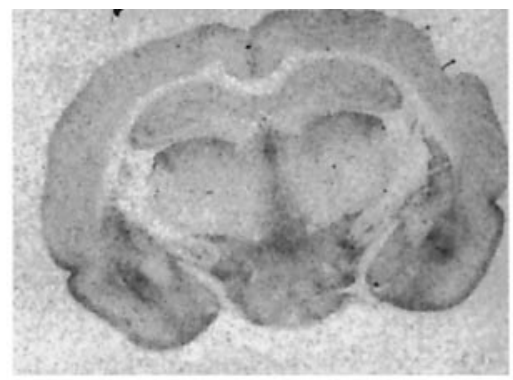

CONTROL

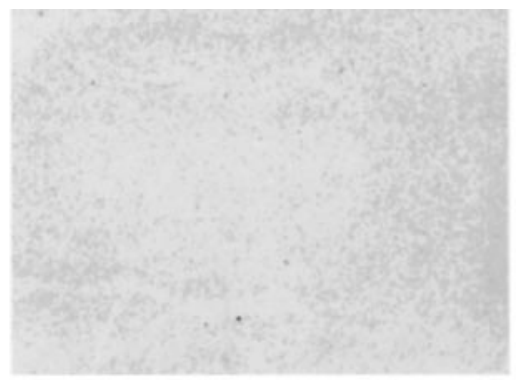

NON-SPECIFIC

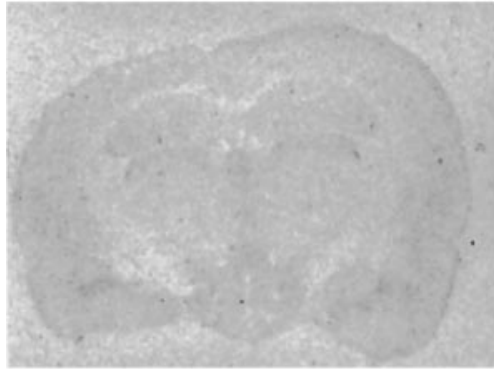

PAROXETINE, $5 \mathrm{mg}$

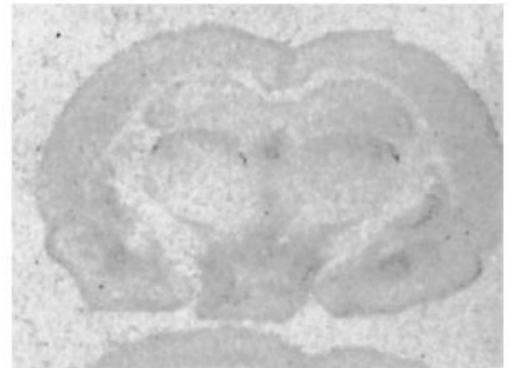

PAROXETINE, $10 \mathrm{mg}$

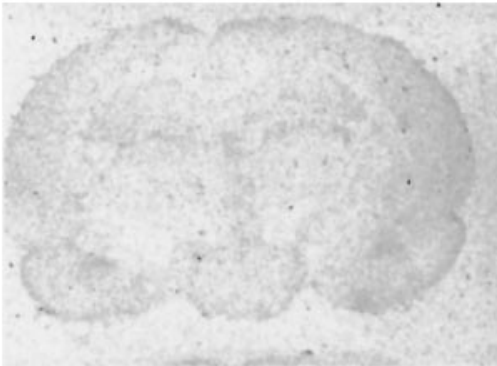

SERTRALINE

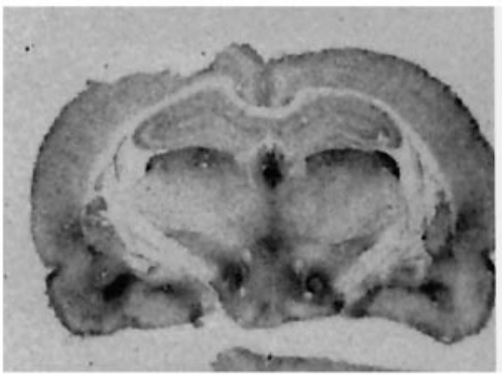

DESIPRAMINE

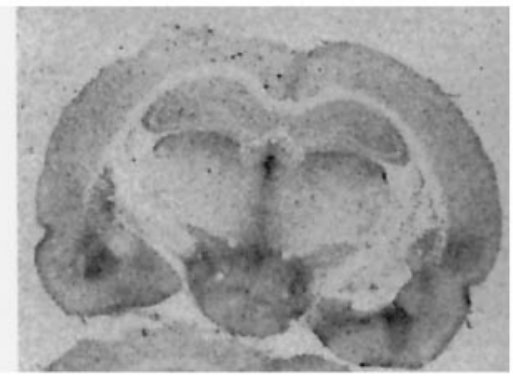

PHENELZINE

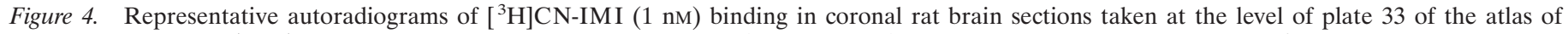
Paxinos and Watson (1986) of control and drug-treated rats. Nonspecific binding defined with sertraline amounted to $<5 \%$ of total binding.

binding, 80-90\%. Unexpectedly, DMI treatment caused a 50\% increase in the binding of $\left[{ }^{3} \mathrm{H}\right] \mathrm{CN}-\mathrm{IMI}$, whereas phenelzine treatment had no significant effect.

\section{Effects on serotonin content}

Chronic treatment of rats with SSRIs had similar effects as lesioning rats with the serotonergic neurotoxin, 5,7-DHT, on 5-HT clearance parameters (Daws et al., 1998) and on SERT density (Hensler et al., 1994). To assess if the effects of the SSRI treatments were caused by a neurotoxic effect, 5-HT and 5-HIAA tissue content were examined in hippocampi of SSRI-treated rats. No significant effect on tissue levels of 5-HT or 5-HIAA in the hippocampus was found (Table 3 ).

\section{Effects on mRNA levels for the SERT}

In situ hybridization histochemistry was used to quantify mRNA levels of the SERT in the raphe nuclei to study if the effects of SSRI treatments were caused by a decrease in SERT gene expression. In Figure 6, representative coronal sections through dorsal and median raphe nuclei show a high level of mRNA labeling of the SERT in the dorsomedial, ventromedial, and lateral portions of the dorsal raphe as well as in the median raphe nucleus, both in a control and paroxetine-treated rat. Treatment with paroxetine $(10 \mathrm{mg} / \mathrm{kg})$ had no significant effect on the mRNA level for the SERT in the median raphe nucleus (Fig. 7); however the $33 \%$ increase in mRNA observed in the dorsal raphe nucleus in the paroxetine-treated rats almost reached significance $(p<0.058 ; t$ test $)$.

\section{DISCUSSION}

A key goal of the present study was to investigate possible functional changes produced by chronic antidepressant treatments on the functioning of the SERT in vivo and to determine if such changes correlate with alterations in the density of the SERT and/or its mRNA levels. To directly assess SERT function, chronoamperometry was used, a technique that examines SERT function in vivo by measuring the clearance of exogenously administered 5-HT. The present study demonstrated that only chronic treatment of rats with the SSRIs paroxetine and sertraline produced changes in SERT function, as evidenced by altered 5-HT 


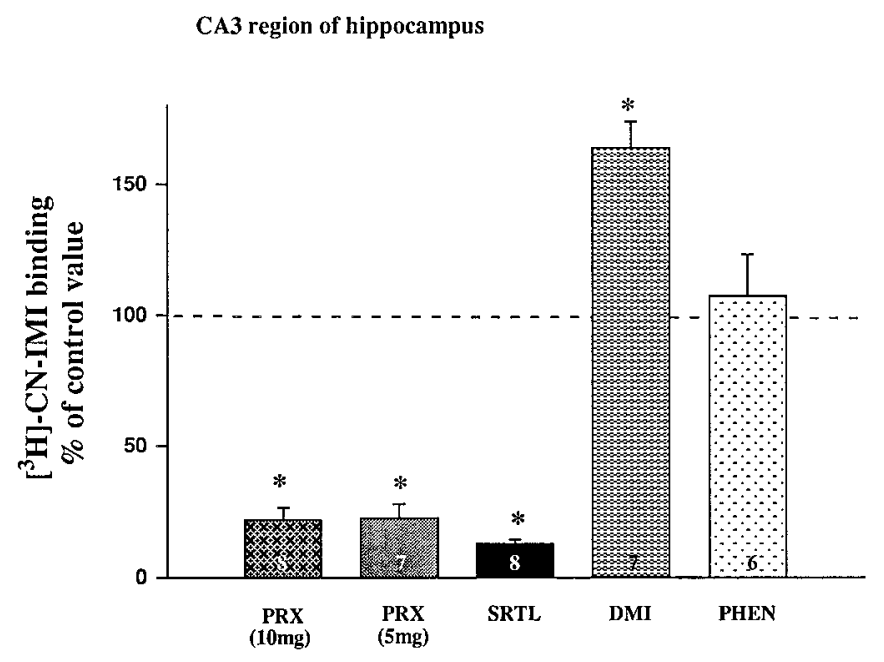

Figure 5. Effects of antidepressants on $\left[{ }^{3} \mathrm{H}\right] \mathrm{CN}$-IMI binding (1 nM) in the CA3 region. Values are expressed as the percentage of the control value $(100 \%)$, which is $351 \pm 42 \mathrm{fmol} / \mathrm{mg}$ protein $(n=15)$. Bars and brackets represent mean \pm SEM. The number of animals per drug-treated group is indicated at the bottom of each bar. ${ }^{*} p<0.01$ comparison of each treatment group with control group, ANOVA, Newman-Keuls post hoc comparison.

\begin{tabular}{|c|c|c|}
\hline Treatment & $5-\mathrm{HT}$ & 5-HIAA \\
\hline Control $(n=10)$ & $180 \pm 8^{a}$ & $191 \pm 7$ \\
\hline Paroxetine $(10 \mathrm{mg})(n=5)$ & $199 \pm 12$ & $222 \pm 11$ \\
\hline Paroxetine $(5 \mathrm{mg})(n=6)$ & $208 \pm 17$ & $188 \pm 12$ \\
\hline Sertraline $(n=4)$ & $205 \pm 14$ & $210 \pm 13$ \\
\hline
\end{tabular}

${ }^{a}$ Mean \pm SEM.

Rats were chronically treated with paroxetine, sertraline, or vehicle. Hippocampi were processed for 5-HT and 5-HIAA content. Chronic treatment with SSRIs did not alter the content of serotonin or its metabolite in hippocampus.

clearance characteristics in response to fluvoxamine and by decreased SERT density.

Results from previous studies that examined the effect of chronic antidepressant treatment on SERT density and mRNA levels have been inconsistent (for review, see Blakely et al., 1997). Such inconsistent results may be attributable, in part, to the class of antidepressant studied, the brain areas analyzed, the route and duration of drug administration, and the washout period. To avoid large fluctuations in drug concentration, most of the antidepressants used in this study were administered subcutaneously by osmotic minipump. Piñeyro et al. (1994) have suggested that stable plasma concentrations of SSRIs are essential for downregulation of the SERT. Furthermore, to ensure that the results would be applicable to the clinical situation, plasma levels of paroxetine, sertraline, and DMI were measured, and drug doses were selected to achieve steady-state concentrations within or near the range recommended clinically (Table 1 ).

Treatment with either paroxetine or sertraline induced a dramatic decrease in $\left[{ }^{3} \mathrm{H}\right] \mathrm{CN}$-IMI binding throughout brain (Fig. 4); quantitation of this effect in the CA3 region of hippocampus revealed an 80-90\% decrease in binding (Fig. 5). A decrease of similar magnitude in SERT density has previously been observed after chronic treatment with paroxetine (Piñeyro et al., 1994). Other investigators (Brunello et al., 1987; Kovachich et al., 1992;
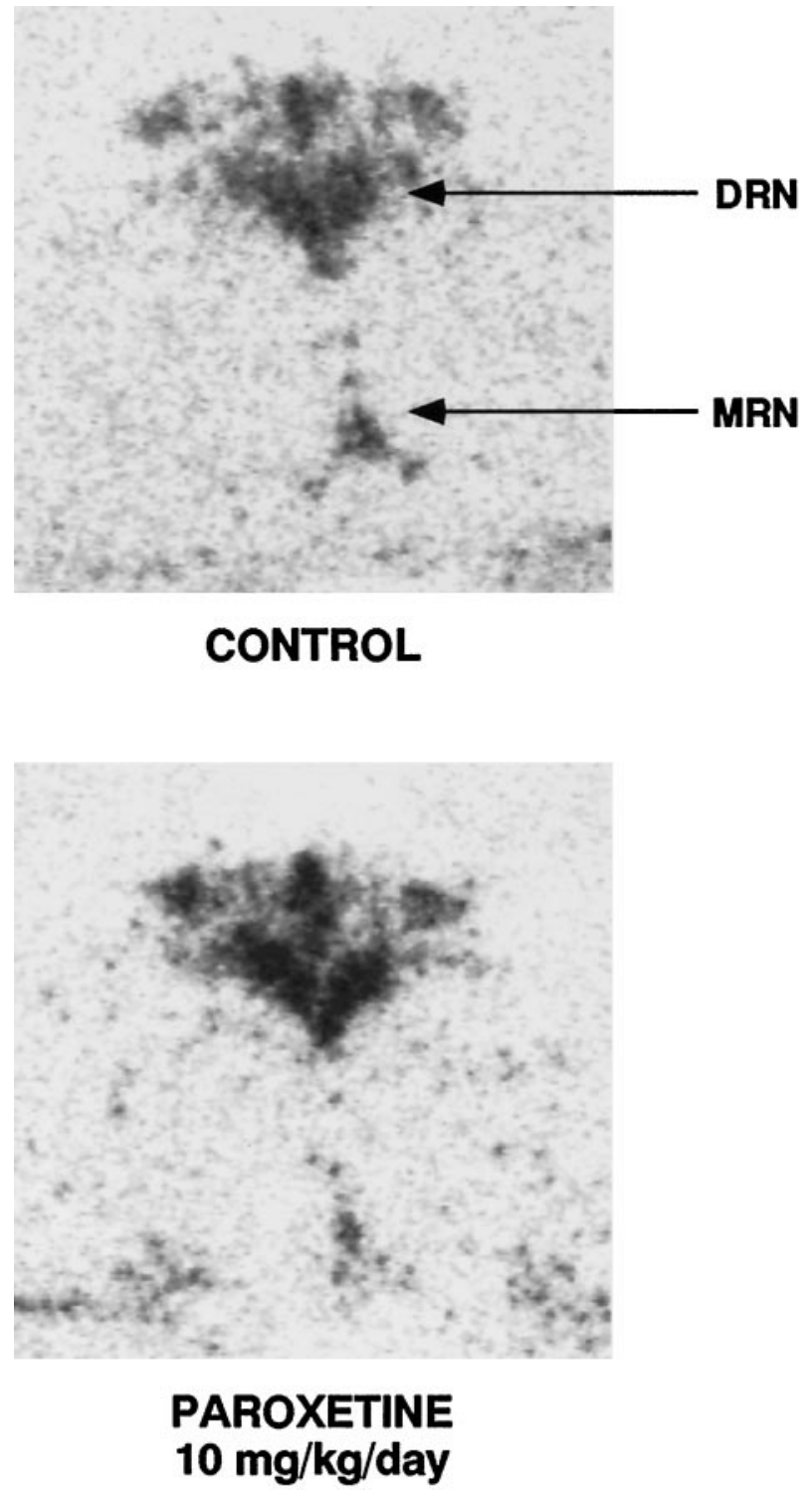

Figure 6. Serotonin transporter messenger RNA in the raphe nuclei of rats detected by in situ hybridization in a control and paroxetine-treated rat $(10 \mathrm{mg} / \mathrm{kg})$. Coronal brain sections were taken at the level of plate 49 of the atlas of Paxinos and Watson (1986). Different levels of labeling were seen in the dorsomedial, ventromedial, and lateral portions of the dorsal raphe nucleus $(D R N)$ complex. High labeling is also found in the median raphe nucleus $(M R N)$.

Watanabe et al., 1993) have found a similar result with other antidepressants, although the effect was of smaller amplitude. However, SERT density has also been reported to not change (Marcusson and Ross, 1990; Cheetham et al., 1993; Gobbi et al., 1997) after chronic SSRI treatment. In these studies, the drugs were administered intraperitoneally, every 12 or $24 \mathrm{hr}$. Because SSRIs have been shown to be rapidly metabolized in rats [for example, citalopram, which was used in many of latter studies has a half-life of $3 \mathrm{hr}$ in rats (Hyttel et al., 1984)], large fluctuations in drug concentrations in plasma could account for the lack of (or small) effect of SSRIs administered intraperitoneally daily. In the present study, stable serum drug concentrations were achieved by means of sustained subcutaneous inf usion via osmotic minipump. Consistent effects on the binding of $\left[{ }^{3} \mathrm{H}\right] \mathrm{CN}-\mathrm{IMI}$ to the SERT were produced by the two SSRIs examined. 


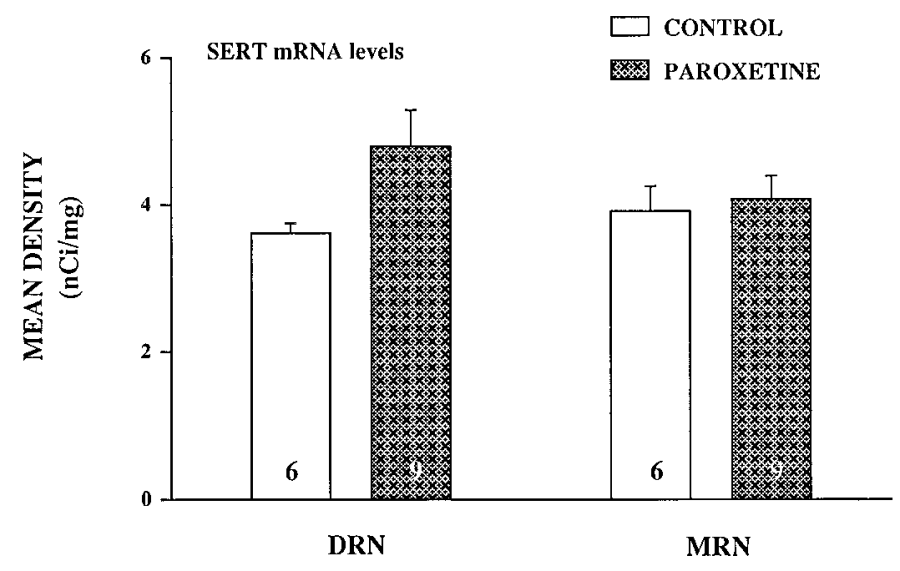

Figure 7. Effect of chronic paroxetine treatment $\left(10 \mathrm{mg} \cdot \mathrm{kg}^{-1} \cdot \mathrm{d}^{-1}\right)$ on the mRNA levels of the SERT in the raphe nuclei. Values for the dorsal raphe nucleus $(D R N)$ and median raphe nucleus $(M R N)$ represent mean integrated density \pm SEM. Number of animals is indicated at the bottom of each bar.

No changes in SERT density were found in rats chronically treated with the MAO inhibitor phenelzine, a result consistent with a previous study that examined the effect of chronic treatment with other MAOIs, clorgyline or selegiline (Yeghiayan et al., 1997). However, treatment with desipramine unexpectedly caused a $50 \%$ increase in $\left[{ }^{3} \mathrm{H}\right] \mathrm{CN}-\mathrm{IMI}$ binding. This DMIinduced increase in SERT density could be the result of interaction between serotonergic and noradrenergic neuronal systems. Long-term administration of norepinephrine reuptake inhibitors has been reported to desensitize $\alpha_{2}$ adrenergic heteroreceptors on serotonin terminals (Mongeau et al., 1994). Such desensitization would decrease a norepinephrine-mediated inhibitory input to serotonin terminals, presumably resulting in an increase in 5-HT transmission.

To assess SERT function in vivo, 5-HT signal recordings were measured within a discrete part of the CA3 region of the hippocampus where the norepinephrine transporter does not play a significant role in removal of exogenously applied 5-HT (Daws et al., 1998). Local application of fluvoxamine significantly prolonged the clearance of 5-HT of control rats or those chronically treated with either phenelzine or desipramine. By contrast, fluvoxamine had no effect on 5-HT clearance in rats treated with paroxetine or sertraline (Fig. 3, Table 2). Thus, consistent with the SSRI-induced reduction in $\left[{ }^{3} \mathrm{H}\right] \mathrm{CN}$-IMI binding, local application of fluvoxamine no longer prolonged the clearance of exogenous 5-HT in these SSRI-treated rats. It would appear that the site of action of fluvoxamine, namely the SERT, is markedly reduced in the SSRI-treated rats.

The reductions of SERT function and density seen with paroxetine treatment (Figs. 3, 5) were similar to those observed after lesioning serotonin neurons with the neurotoxin 5,7-DHT (Hensler et al., 1994; Daws et al., 1998). Therefore, it seemed necessary to examine if chronic treatment with SSRIs produced the observed reduction in SERT function and density because of a toxic effect on 5-HT neurons. No reduction in the hippocampal content of 5-HT in paroxetine-treated rats was observed (Table 3) in contrast to the $90 \%$ reduction in 5-HT hippocampal content observed after lesioning with 5,7 DHT (Daws et al., 1998). This indicates that a neurotoxic mechanism is probably not responsible for the SSRI-induced reduction in SERT function and density.

In addition to protein synthesis, another important aspect of neuronal regulation is control of gene expression. In the present study, chronic administration of paroxetine failed to significantly alter mRNA level of SERT in the raphe nucleus (Figs. 6, 7). Similar findings have previously been reported based on either Northern blot analysis (Spurlock et al., 1994; Linnet et al., 1995; Koed and Linnet, 1997) or in situ hybridization histochemistry (Burnet et al., 1994; Neumaier et al., 1996; Swan et al., 1997). However, a few studies have reported that mRNA levels of SERT are increased (Lopez et al., 1994) or decreased (Lesch et al., 1993) after antidepressant treatments. Again, differences between studies may reflect differences in the administration schedule of the drugs as well as other factors noted above.

Although the mRNA hybridization signal for the SERT in the raphe nucleus was not altered by chronic paroxetine treatment, we cannot exclude the possibility of a transient alteration in mRNA expression during the earlier stages of antidepressant treatment. Indeed, Neumaier et al. (1996) reported a temporary reduction in SERT mRNA that was observed after $7 \mathrm{~d}$ of treatment with fluoxetine but not after $21 \mathrm{~d}$. Consistent with this possibility, Rattray et al. (1996) have shown that serotonin depletion induced a rapid decrease in mRNA levels of the SERT $2 \mathrm{~d}$ after $p$-chlorophenylalanine treatment, which was followed by an increase $7 \mathrm{~d}$ later. However, a decrease in ligand binding to the SERT was measurable only after $14 \mathrm{~d}$. Such data showed that changes in the mRNA levels of the SERT are not temporally related to changes in SERT protein levels. At any rate, our data suggest that the decrease in SERT function and density are not attributable to a decrease in gene expression.

The mechanism by which SSRIs such as paroxetine and sertraline downregulate the SERT is not currently known. Long-term SSRI administration could induce regulation at the posttranslational level. Using heterologous expression systems, Qian et al. (1997) have shown that stimulation of protein kinase C (PKC) causes internalization of cell-surface SERT protein. SERT phosphorylation via PKC stimulation was shown to occur in tandem with a reduction in 5-HT uptake capacity (Ramamoorthy et al., 1998). Interestingly 5-HT itself reduced the PKC-mediated phosphorylation and internalization of the SERT and SSRIs blocked the effect of 5-HT (Ramamoorthy and Blakely, 1999). Thus, 5-HT may have a direct effect on the SERT to maintain or even increase its density at the plasma membrane and SSRIs could shift the cellular distribution of the SERT. It is not presently known what other kinases can downregulate the SERT by its phosphorylation. It is of interest, though, that the activity of $\mathrm{Ca}^{2+} /$ calmodulindependent kinase type II in the hippocampus of rats is increased by chronic administration of SSRIs (Popoli et al., 1995).

There is at least one interesting potential clinical implication of these data. There seems to be some proportion of depressed patients who respond beneficially to SSRI treatment but in whom the benefit wanes over time (Byrne and Rothschild, 1998). One wonders if this may be attributable to a drug-induced loss of the SERT, such that the initial cellular target responsible for the beneficial effect of SSRIs is markedly diminished. This phenomenon has not been well-studied with controlled trials (Byrne and Rothschild, 1998). Somewhat more extensively studied, but again not with controlled trials, has been subsequent response of SSRInonresponders (Thase and Rush, 1997; Thase et al., 1997). It does appear that either raising the dose of the SSRI or switching to a different SSRI is successful, in perhaps $40-70 \%$ of the patients. Although quite speculative, perhaps SSRI-induced loss of the SERT provides part of the explanation of why some patients do not respond to such strategies. 
In conclusion, the therapeutic efficacy of SSRI and non-SSRI antidepressants probably derives from different adaptive changes. The SSRIs (paroxetine and sertraline) decrease SERT density and reduce SERT function, as indicated by failure of fluvoxamine to prolong 5-HT clearance. Whether this is produced by all SSRIs remains to be established. Nevertheless, non-SSRI antidepressants gave no evidence of altering SERT function and did not decrease SERT density.

\section{REFERENCES}

Auerbach SB, Hjorth S (1995) Effect of chronic administration of the selective serotonin (5-HT) uptake inhibitors citalopram on extracellular 5-HT and apparent autoreceptor sensitivity in rat forebrain in vivo. Naunyn Schmiedebergs Arch Pharmacol 352:597-606.

Blakely RD, Ramamoorthy S, Qian Y, Schroeter S, Bradley CC (1997) Regulation of antidepressant-sensitive serotonin transporters. In: Neurotransmitter transporters. Structure, function and regulation (Reith MEA, ed), pp 29-72. Totowa, NJ: Humana.

Blier P, Bouchard C (1994) Modulation of 5-HT release in the guineapig brain following long-term administration of antidepressant drugs. Br J Pharmacol 113:485-495.

Brunello N, Riva M, Volterra A, Racagni G (1987) Effect of some tricyclic and nontricyclic antidepressants on $\left[{ }^{3} \mathrm{H}\right]$ imipramine binding and serotonin uptake in rat cerebral cortex after prolonged treatment. Fundam Clin Pharmacol 1:327-333.

Burnet PWJ, Michelson D, Smith MA, Gold PW, Sternberg EM (1994) The effect of chronic imipramine administration on the densities of 5-HT1A and 5-HT2 receptor and the abundancies of 5-HT receptor and transporter mRNA in the cortex, hippocampus and dorsal raphe of tree strain of rats. Brain Res 638:311-324.

Byrne SE, Rothschild AJ (1998) Loss of antidepressant efficacy during maintenance therapy: possible mechanisms and treatments. J Clin Psychiatry 59:279-288.

Cheetham SC, Viggers JA, Slater NA, Heal DJ, Buckett WR (1993) $\left[{ }^{3} \mathrm{H}\right]$ paroxetine binding in rat frontal cortex strongly correlates with $\left[{ }^{3} \mathrm{H}\right] 5$-HT uptake: effect of administration of various antidepressant treatments. Neuropharmacology 32:737-743.

Daws LC, Toney GM, Gerhardt GA, Frazer (1998) In vivo chronoamperometric measures of extracellular serotonin clearance in rat dorsal hippocampus: contribution of serotonin and norepinephrine transporters. J Pharmacol Exp Ther 286:967-976.

Domyancic AV, Morilak DA (1997) Distribution of $\alpha_{1 \mathrm{~A}}$ adrenergic receptor mRNA in the rat brain visualized by In situ hybridization. J Comp Neurol 386:358-378.

Frazer A (1997) Pharmacology of antidepressants. J Clin Psychopharmacol 17:2S-18S.

Frazer A, Morilak DA (1998) Drugs for the treatment of affective (Mood) disorders. In: Human pharmacology. Molecular to clinical (Brody TM, Larner J, Minneman KP, eds), pp 349-362. New York: Mosby.

Gerhardt GA, Oke AF, Nagy G, Moghaddam B, Adams RN (1984) Nafion-coated electrodes with high selectivity for CNS electrochemistry. Brain Res 290:390-394.

Gobbi M, Crespi D, Foddi MC, Fracasso C, Mancini L, Parotti L, Mennini $\mathrm{T}$ (1997) Effects of chronic treatment with fluoxetine and citalopram on 5-HT uptake, 5-HT1B autoreceptors, 5-HT3 and 5-HT4 receptors in rats. Naunyn Schmiedebergs Arch Pharmacol 356:22-28.

Hall ME, Hoffer BJ, Gerhardt GA (1989) Rapid and sensitive determination of catecholamines in small tissue samples by high performance liquid chromatography coupled with dual-electrode coulometric electrochemical detection. Liquid Chromatography/Gas Chromatography 7:258-265.

Hensler JG, Ferry RC, Labow DM, Kovachich GB, Frazer A (1994) Quantitative autoradiography of the serotonin transporter to assess the distribution of serotonergic projections from the dorsal raphe nucleus. Synapse 17:1-15.

Hrdina PD, Vu TB (1993) Chronic fluoxetine treatment upregulates 5-HT uptake sites and 5-HT2 receptors in rat brain: an autoradiographic study. Synapse 14:324-331.

Hyttel J, Overo KF, Arnt J (1984) Biochemical effects and drug levels in rats after long-term treatment with the specific 5-HT uptake inhibitor, citalopram. Psychopharmacology 83:20-27.

Kaye CM, Haddock RE, Langley PF, Mellows G, Tasker TC, Zussman BD, Greb WH (1989) A review of the metabolism and pharmacokinetics of paroxetine in man. Acta Psychiatr Scand 80:60-75.
Koed K, Linnet K (1997) The serotonin transporter messenger RNA level in the rat brain is not regulated by antidepressants. Biol Psychiatry 42:1177-1180.

Kovachich GB, Aronson CE, Brunswick DJ, Frazer A Q (1988) Quantitative autoradiography of serotonin uptake sites in rat brain using $\left[{ }^{3} \mathrm{H}\right]$ cyanoimipramine. Brain Res 454:78-88.

Kovachich GB, Aronson CE, Brunswick DJ (1992) Effect of repeated administration of antidepressants on serotonin uptake sites in limbic and neocortical structures of rat brain determined by quantitative autoradiography. Neuropsychopharmacology 7:317-324.

Kuroda Y, Watanabe Y, McEwen BS (1994) Tianeptine decreases both serotonin transporter mRNA and binding sites in rat brain. Eur J Pharmacol Mol Pharmacol 268:R3-R5.

Lesch PK, Aulakh CS, Wolozin BL, Tolliver TJ, Hill JL, Murphy DL (1993) Regional brain expression of serotonin transporter mRNA and its regulation by reuptake inhibiting antidepressants. Mol Brain Res 17:31-35.

Linnet K, Koed K, Wiborg O, Gregersen N (1995) Serotonin depletion decreases serotonin transporter mRNA levels in rat brain. Brain Res 697:251-253.

Lopez JF, Chalmers DT, Vazquez DM, Watson SJ, Akil H (1994) Serotonin transporter mRNA in rat brain is regulated by classical antidepressants. Biol Psychiatry 35:287-290.

Marcusson JO, Ross SB (1990) Binding of some antidepressants to the 5 -hydroxytryptamine transporter in brain and platelets. Psychopharmacology (Berl) 102:145-155.

Mongeau R, de Montigny C, Blier P (1994) Electrophysiologic evidence for desensitization of $\alpha 2$-adrenoceptors on serotonin terminals following long term treatment with drugs increasing norepinephrine synaptic concentration. Neuropsychopharmacology 10:41-51.

Neumaier JF, Root DC, Hamblin MW (1996) Chronic fluoxetine reduces serotonin transporter mRNA and 5-HT1B mRNA in a sequential manner in the rat dorsal Raphe nucleus. Neuropsychopharmacology 15:515-522.

Paxinos G, Watson C (1986) The rat brain in strereotaxic coordinates. New York: Academic.

Piñeyro G, Blier P, Dennis T, de Montigny C (1994) Desensitization of the neuronal 5-HT carrier following its long-term blockade. J Neurosci 14:3036-3047.

Popoli M, Vocaturo C, Perez J, Smeraldi E, Racagni G (1995) Presynaptic $\mathrm{Ca}^{2+}$ /calmodulin-dependent protein kinase II: autophosphorylation and activity increase in the hippocampus after long-term blockade of serotonin reuptake. Mol Pharmacol 48:623-629.

Qian Y, Galli A, Ramamoorthy S, Risso S, DeFelice LJ, Blakely RD (1997) Protein kinase $\mathrm{C}$ activation regulates human serotonin transporters in HEK-293 cells via altered cell surface expression. J Neurosci 17:45-57.

Ramamoorthy S, Blakely RD (1999) Phosphorylation and sequestration of serotonin transporters differentially modulated by psychostimulants. Science 285:763-766.

Ramamoorthy S, Giovanetti E, Qian Y, Blakely RD (1998) Phosphorylation and regulation of antidepressant-sensitive serotonin transporters. J Biol Chem 273:2458-2466.

Rattray M, Baldessari S, Gobbi M, Mennini T, Samanin R, Bendotti C (1996) $p$-Chlorophenylalanine changes serotonin transporter mRNA levels and expression of the gene product. J Neurochem 67:463-472.

Spurlock G, Buckland P, O'Donovan M, McGuffin P (1994) Lack of effect of antidepressant drugs on the levels of mRNAs encoding serotonergic receptors, synthetic enzymes and 5HT transporter. Neuropharmacology 33:433-440.

Swan MC, Rahman Najlerahim A, Bennet JP (1997) Expression of serotonin transporter mRNA in rat brain: presence in neuronal and nonneuronal cells and effect of paroxetine. J Chem Neuroanat 13:71-76.

Thase ME, Rush JA (1997) When at first you don't succeed: sequential strategies for antidepressant nonresponders. J Clin Psychiatry 58:23-29.

Thase ME, Blomgren SL, Birkett MA, Apter JT, Tepner RG (1997) Fluoxetine treatment of patients with major depressive disorder who failed initial treatment with sertraline. J Clin Psychiatry 58:16-21.

Tulloch IF, Johnson AM (1992) The pharmacologic profile of paroxetine, a new selective serotonin reuptake inhibitor. J Clin Psychiatry 53:7-12.

Watanabe Y, Sakai RR, McEwen BS, Mendelson S (1993) Stress and antidepressant effects on hippocampal and cortical 5-HT1A and 5-HT2 receptors and transport sites for serotonin. Brain Res 615:87-94.

Yeghiayan SK, Andersen SL, Baldessarini RJ (1997) Lack of effect of chronic clorgyline or selegiline on dopamine and serotonin transporters in rat caudate-putamen or nucleus accumbens septi. Neurosci Lett 236:147-150. 